\title{
Contemporary Techniques of English Language Learning in the Age of Global Communication Technologies
}

\author{
Hassan Bin Zubair \\ PhD Scholar \\ English Literature, Department of English \\ National University of Modern Languages \\ Islamabad, Pakistan \\ hbz77@yahoo.com
}

\begin{abstract}
This research explores the importance of motivation and how it plays an important role in language learning. This motivation can vary from person to person, according to the factors which he or she is surrounded by. Some factors can affect motivation intrinsically or some factors can affect in motivation extrinsically in language learning. The aim of this study is to find out the factors behind Pakistani students' motivation to learn English. The researcher has used qualitative multiple case study approach, to study fifteen students in order to get the information by conducting interviews. The fifteen students were from three different age groups, and there are 10 to 12 years, 14 to 16 years and 20 to 25 years old. The findings show how the factors affect students' motivation in language learning. Some of the factors are mandatory subject, students' participation, teachers' feedback, and limited study materials. These factors can be helpful to find out the effective way to motivate the students to learn target language, the teachers' technique and also benefit the
\end{abstract}


involvement of parents in the student's life.

Keywords: English, Language, Learning, Motivation, Techniques, Age Groups, Pakistan.

1. Introduction

English is acknowledged and thought to be a great opportunity for people and the society they are living in. They also mentioned that for the global economic purpose, English is used to access into central economic market, mentioned in Chowdhury \& Kabir (2014).Moreover, in the Asian countries, people are learning the language as a foreign language for decades now. These countries are adopting the techniques of learning and teaching the language in their education policy so that they also connect with global trade and commerce. In other Asian countries like India, English can be used as a lingua franca, however in Pakistan it can never be English and is mostly used as global networking language in the country (Rahman, 2005). In Pakistan, people are generally forced to use English for particular purposes for example administrative, professional or educational sectors (Rahman, \& Karim, 2015). Critics have pointed out that English was forced in Pakistan because of the British colonial education system. However, English is being used in Pakistan for years now, for different purposes, one of which is having a social standard that sets people apart in the society. In other words, knowing the language better gives a person a status and social advantage. Being able to use English language gives better option in job sectors, building a successful career, or going in to foreign country to study for the further study (Rahman, 2005). Masum (2016) had mentioned that the communication approach has been introduced in Pakistan education system to give the students a chance to practice English in 1900s. Yet, current students are not able to communicate or write in Basic English after 12 years of their education that as English as a mandatory subject. He also mentioned that there is a need of exploring in the nature of motivation when it is closely related to language learning.

Pakistanis have limited exposure to the language. For instance, they rarely get the 
chance to interact with the native speakers or their cultural community. In addition, Urdu medium schools tend to use only a limited amount of novels, books or English movies, which does not help them attain English properly (Rahman, 2012). This study will be focusing on the factors that affect the nature of the motivation, which can be effective for the second language learner of different ages.

\subsection{Problem Statement}

Ahmed, (2012) mentioned that there were changes in the teaching techniques in the Pakistani education system, and yet the students are not really developing in terms of learning English. In Pakistan, English is a compulsory subject for students from class 1 to 12 under national curriculum (Chowdhury, 2003), but even after this they are still not able to communicate or write something in English without memorizing it after. Most of the students are not intrinsically motivated in learning English, when they are forced; they are usually motivated for specific purposes only (Masum 2016, p. 182). This study aims to find out the factors behind Pakistani students' motivation to learn English. These factors can be helpful to find out the effective way to motivate the students to learn the target language.

\subsection{Purpose of Study}

The study will be to find out the factors that affect the students in second language learning at different ages in the context of Pakistan. This research will contain the difference of the motivation between three groups of students. The groups are group 1.11 to 12 , group 2.14 to 15 years old and group 3.19 to 22 years old. The purpose of the study is to find out the different factors that affect motivation to learn target language.

1.3 Research Question.

1: Which factors affect the nature of motivation of secondary school students? 
2: Which factors affect the nature of motivation of higher secondary school students? 3:

Which factors affect the nature of motivation of university fresher students?

\subsection{Significance of the study}

This study focuses on the factors, which affect the motivation for language learning of students of different age groups. Teacher and parents contribute in motivating the students in the language learning (Skinner and Belmont, 1993). This study is focused on the factors on how the students can be motivated in learning language. Therefore, the teacher or the lesson planner could make changes in the techniques or in the materials to make sure that the students are being encouraged to learn a new language. This study can also be helpful for the parents to motivate their children rather than forcing them to learn English. It also will be helpful for the students themselves to find their motivation according to their personalities, and their attitude towards to learning language.

\subsection{Delimitation}

The data were collected from different schools by conducting interview from three different age groups. The researcher chose those schools where she has easy access. The last student participants were from a private university's Department of English where the researcher studies.

The reason for choosing them was they were studying English and the researcher wanted to see why they were motivated to learn English. Moreover, being from the same department, it was easy for the researcher to reach the participants.

\subsection{Limitation}

In one of the schools, the teachers were standing in front of the students while taking the interview. Therefore, the students were nervous to answer and they were 
hesitating to answer the questions. The second problem faced by the researcher is the younger students were hesitating to answer in the first place. Researcher had to suggest the options to them, and then they were able to answer. As the researcher used two interviewees at a time for the secondary and higher secondary students because the limited time was given to the researcher, the second person sometimes said "same here" or copied the answer from the 1st interviewee.

\section{Literature Review}

Motivation provides the main principle to learn a second language which makes mark on the language learning process and also the other factors which require the present of motivation in language learning. Without enough of motivation in language learning, it is difficult to achieve the long-term goal with the individual extraordinary capabilities and good environment and good teaching methods (Dörnyei 1998, P. 117). He also mentioned that, the researchers are agreeing that motivation is one the factors which helps a student to get the direction in the process of language learning (p.117). Csizér, Kormos (2008) said, the students with high motivation towards to language learning might be advantage in the various from of language skill, and they will have engaged themselves with the four skills of language learning.

Dörnyei \& Ushioda (2013) cited Wallace Lambert and Robert Gardner with regard to their work on L2 motivation and found that motivation in learning language is one of the primary factors that would make difference in language learning and in the field of communication. This idea is with some key factors which are including individual perception towards to L2 and towards to the L2 culture and people, which can be influenced in language learning. As reported by Gardner and Lambert (1972), there are two kind motivations of learning motivation: integrative motivation which is learning a language by being interested in language and instrumental which is a language for 
future goal .Gardener (1985) stated that integrative orientation is related to perception to towards to the L2 and the L2 community and integrative motivated learners would "demonstrate greater motivational effort in learning L2" therefore they will succeed in learning the second language. Noels, Clément, \& Pelletier, (2001) stated that, the integrative motivation is parallel with independent motivation; therefore, it can be said that who want to learn a new language as it is enjoyable to them and also desirable to them to interact with the community. Their finding shows that intergroup might be encouragement for the students and their interest in learning a new language. Ryan \& Deci (2000) and Dörnyei, \&Ushioda, (2013) defined intrinsic as it is as a selfsatisfaction than being pressurized. He also mentioned the new language learners are the intrinsically motivated people who are interested in the language rather than learning the new language because of external pressure or rewards. To define extrinsic motivation, Ryan \& Deci (2000) said in their article that it is opposite of intrinsic motivation, which means doing activities for own pleasure, whereas the extrinsic motivation is a behaviour which can be said as "invariantly non autonomous" (P. 60). They also exemplified of extrinsic motivation by stating, if a language learner does their work in order to meet the especial outcome like to have good grade in class work, or fear of parental fear. Another similar situation is given that if a student wishes to learn a new language which can be valuable for the career can be also counted as extrinsic motivation Dörnyei \& Ushioda, (2013) mentioned the second motivation which is extrinsic means "to some separable end, such as receiving an extrinsic reward (e.g. good grades) or avoiding punishment" (P. 23). They also included the extrinsic value, that is "awareness of how well a task relates to current and future goals and what role learning plays in improving the quality of one's or making one a better person" (P. 19). Zhao (2011) mention in his article, the intrinsic motivation has advantage as predictor of affective variables, which includes low level of anxiety, positive attitude towards to target language learning and it also gives the self- confident to use the 
target language.

Williams, Burden \&Lanvers (2002) stated that there are less research has been made related with age than gender difference in the area of language learning; however, there is a tendency to different motivation with age. Lucas et al (2010) mentioned the constructive relationship between the learner's intrinsic motivation and the new language they are learning which is English and this target language has impact on the academic purpose and also in the community where they moved. This tendency of learning English through the use of the reading, speaking and listening skill is due to the learners' positive attitude and "inclination towards assimilation, mastery and spontaneous interest to this language" because of their exposure to the target language environment in early age (P. 17). Williams, Burden \& Lanvers (2002) mentioned there are indications that the presence of cognitive and metacognitive awareness in language learning is importance, but little evidence of that "the respondents actually used metacognitive strategies" (P. 521). They mentioned about the 7 to 9 years old students who had he higher degree of integrative motivation to learn a new language

Kormos, \&Csizér (2008) said that the biggest distinction between the age groups can be found in language learning in motivation behaviour. He also added that the students of the secondary school choose a foreign language to study only for the school studies, which is compulsory, and for the university students, is also mandatory to learn a language without that they can't complete diploma "until they obtain the prerequisite language certificates. However, the adult students survive in the university as they might have taken that course in the school and their cognitive level is high, they might experience the own pleasure in the free time reading in the target language. The adults also are interested in target language as it is valuable in the job market. He also mentioned that, "despite the fact that the mean value for the motivation behaviour and language learning attitude are lower the case of secondary school students" than the group of older people (p. 348- 349). 
Pakistani education system has four levels, which are primary, secondary, higher secondary, tertiary; using two languages as medium of instruction. The syllabus and other materials from the primary to higher secondary are created by the National Curriculum and Textbooks Board said Masum, (2016). He also mentioned about the teaching method which was followed by the English teachers in the English class was Grammar translation method; however, the communication approach has been introduced to the Pakistan education, so that the students can practice the target language more (p. 177-178).

In Pakistan, English is used as a foreign language as Chowdhury and Kabir (2014) said. This language is taught to all students as a subject in 12 years of school life under a national curriculum where mostly teach the grammar of the language, translation and how to read in English language (Islam \& Bari, 2012, p. 89). In this curriculum, speaking is not important, and all the students try to memorize the materials for the exams only. However, the language teaching techniques are changing day by day, they are trying to develop new strategies for teaching and learning the language. Ali (2011) explained that the national curriculum of Pakistan included the topics, which are related to the real life and global situation, and related to the Pakistani culture so that the ELT curriculum becomes learnercentered and the students become enriched in knowledge (p. 290).

There are no qualitative researches, which explore the relation and the factors affecting student's language learning in the context of Pakistan. Therefore, this study seeks to fulfil the gaps to find out the affecting factors in the nature of motivation in language learning.

\section{Research Methodology}

It describes of the research methodology adopted for conducting this study. It has been composed of the methodology that had been used in this research paper, which will include the rationale behind choosing the research pragmatic, it's philosophy, research design, setting, selecting the participant, data collection procedure, data analysis procedure, 
ethical consideration, and thrust worthiness of the study. The first research question investigates which factors affect the nature of motivation of secondary school students. The second research question explores to find out which factors affect the nature of higher secondary school students. The third research question seeks to find out which factors affect the nature of the motivation of students of tertiary level.

\section{1. Research Design}

The research is a qualitative research which is an approach where open questionnaire required (Friedman, 2012). This approach also included observation of the behaviour of the students while the interview, students experience with the target language, interaction interview, life story of the interviewee (Denzin \& Lincoln 2008). Creswell (2012) added that, qualitative research relies on interviews or observation, which cannot restrict the participants' point of view and the information do not stay in specific categories, is analysis of the central phenomenon. Therefore, the researcher gets most of the information about the participants and the results of the research are descriptive. A case study method helps the researcher to see or examine the data from the participants within the specific context. Zainal (2007) also mentioned that a case study includes a small area and specific number of contents. In this research, Pakistan is the geographical area and the researcher is trying to find out how a specific number of students' nature of motivation changes through their age level. He also added that the case study is the true essence of examination of "real-life phenomenon through detailed contextual analysis of a limited of even or condition". In this research, the researcher tried to find out the real life phenomenon, which is why the students are not intrinsically motivated in language learning, and whether the nature of the motivation changes as the age level changes. Therefore, the researcher adopted the multiple case study methods, which can be with real life events and show enough evidence "rather than sampling the logic" (Zainal, 2007. p. 2) 


\subsection{Setting}

The researcher conducted the study among ESOL the students who live in Islamabad, Pakistan. These students have a common language to use in regular life. Moreover, they learn English as a subject in their school. The researcher has selected three groups of students from different age groups. The first group included the students age of 10 to 12 years, the second group included students of age of 14 to 16 year olds and the last group included with 20 to 25 year olds. The researcher used saturation point, whenever repetition of theme was occurring in the data collections process. The saturation point was developed by Glaser and Strauss (1967) which is an approach to qualitative research and focuses on developing a theory from the data collection while collecting the data. (Hennink, Kaiser, \&Marconi, 2017). This theoretical saturation occurs when there are some patterns in the data from the interview. (Guest, Bunce, \&Johnson. 2006). The researcher adopted the snowball sampling techniques, which refers to get information through contact provided by other informants (Noy, 2008). The researcher had contact with an informant who was an ex-student of the schools where she found students. The criteria of those students had to be aged between 10 to 13 and 14 to 16 year old, and those who were willing to do the interview. The researcher asked a friend of her if anyone who is fresher, he knows of the 1 st interviewee provided next three interviewees for the researcher.

\section{Data Collection Procedure}

\subsection{Interview}

Interview is one of the renowned data collecting processes in qualitative research. Creswell (2012), mentioned qualitative interview is when a researcher asked open ended to interviewee and transcribe then in a file and analyse them.

The researcher had used semi-structure interview to collect the data. Semi interview is planned to have some prepared question before the interview where there can be enough 
place to ask some other open ended questions based on the participants' questions. (Wengraf 2001). The interviewer asked the interviewee open-ended question. Creswell (2012) mentioned that this kind of question pattern helps the research to get the useful information to "support the theories and concept in the literature" (p.220). The researcher also used audiotape to record the conversation between the interview and interviewee, which is suggested by Creswell (2012) to get the accurate transcript from the interview. The researcher had followed the IPR framework, which was developed by Castilo-Montya, (2016), she mentioned that this framework works for structured or semi-structured interview. In the study, the researcher used the semi-structured interview for three different age groups. The author developed four phases, which are given below:

"Phase 1: Ensuring interview questions aligned with research questions. Phase 2: Constructing an inquiry-based conversation.

Phase 3: Receiving the feedback on interview protocols.

Phase 4: Piloting the interview protocol" (Castilo-Montya, 2016. P. 812).

Phase 1: The researcher made sure that the interview questions represent the research questions. The researcher checked the interview questions whether the questions have coherence with the research topic, which is a motivation to learning a new language.

- Phase 2: In the second phase, the researcher made sure that the interview questions were in chronological manner so that the results of interviews come out as a normal conversation and the participants do not get confused with the questions.

- Phase 3: In the third part, the researcher contacted with an expert who is the lecturer of English department of a private university of Pakistan. She had guided to make the interview question in chronological order and to get the permission letter to conduct interview in different schools and universities.

- Phase 4: The fourth phase is to do a pilot study, which can identify problems in the procedure of collecting for the study, the pilot study does not give the assurance of being 
successful in the main interview; however, it gives the high chance of success of the main study. (Van Teijlingen, \& Hundley, 2001)

\section{Data Analysis}

The researcher adopted the interpretive analysis, which interpreted the data and made the themes, which seek to understand the phenomenon which has been studied in the study Sargeant, (2012). He also mentioned that this interpretation can guide to the extensive grasp on the results of the study. Therefore, the researcher chose to analyze the data with interpretative analysis to the factors, which affect the nature of motivation in learning second language. Miles, Huberman, Huberman, \& Huberman (1994) said that interpretative analysis' has 3 steps and those are: deconstruction, interpretation and the reconstruction (as cited in Sargeant 2012). The researcher has followed the step to analyse the data from the interview. In the 1st step, the researcher made transcript of the interview conversation manually as she had to translate Urdu to English language.

After the transcription, the conversations were codified. The researcher made themes out of coding (appendix- E) In the 2nd steps, the researcher interpreted the data, comparing the data codes with the different interviewees, finding the difference and the similarities between the themes. In the $3 \mathrm{rd}$ step, the researcher reconstructed the themes into the prominent theme, which shows the relationship between the themes and codified conversation. For qualitative research, trust and creditable is important. Pandey\& Patnaik (2014) and Morse, Barrett, Mayan, Olson, \& Spiers, (2002) mention about importance of trustworthy and creditable of a qualitative study where there is no solid number is not present. They also mentioned where Lincon and Guba (1985) talks about trustworthy being involved in building up credibility, transferability, dependability and conformability, which are important for a qualitative research. These elements also have some techniques to make a qualitative research trustworthy. To build up trust and credibility of this 
qualitative study, the researcher followed few techniques. The researcher adopted the interrating reliability, which gives the quantified number in agreeing or disagreeing on coding by multiple inter-rater (Hallagren (2012). In the first section, the researcher will have a brief discussion about the educational background of participants of this study. The researcher will be describing the participants as a group. In the second section, the researcher will show the students' responses to the interview questions and hear their opinions regarding it. The responses will provide the factors which are related to motivation to learn a new language and the learner age.

The researcher interviewed these secondary students, who are young and whose age is between 10 to 12 years. They have recently started their secondary schooling with new excitement and to explore new things. These students were eager to be a part of the interview while the researcher was having a little conversation about the interview and explaining the contents of the contract. The excitement did not last for long, which could be seen when the researcher started to ask questions they were quiet and answering with minimal words especially the 1 st two participants. The five students of secondary level, who were interviewed, mentioned that they like Mathematics. They do not like the grammar part; however, they like the part where the teacher tells them stories in Urdu. There are a few elements that were found during this interview session. The first element is that the students do not like the subject, English, especially the grammar part. The interviewee asked that, "Do you like English as a subject", and one of the students replied that "I like it... but don't like grammar" (DU AMI 10). These students love to hear stories and enjoy it in the class especially when they understand it. These students were asked about why they are learning English, and most of them answered that it is a mandatory subject, therefore they have no option.

Interestingly, they almost started with "English is an international language"; however, in the end they mentioned that "And of course it is a subject which is mandatory, if it was not 
given to us, we would learn it" (DU AMI 25). The researcher found out that the students have to memorise some paragraphs for their English exam. One of the paragraphs they have read before the interview was Importance of English when the researcher was having the conversation before the interview took place.

These students are facing one of the many problems in education, which is almost no time to read any book for pleasure, or watch movies in their free time. One of the students said "I don't really read books except the textbooks as we don't get that much of free time. However, I like to read the stories from the text book" (DU AMI 28). Haider (2012) said that students need to have extensive reading in order to improve their reading skills and also mentioned that there are materials which were provided from grade 6 to 8 for extensive reading called "Rapid Reader" (p. 127) by the NCTB. This book is no longer available to the students. He also has stated that extensive reading can improve an individual's English, such as, in the area of spelling, grammar structure without being explained in the class. The reason for not being able to have even a bit of time for pleasure reading outside of the class is also that the students are all busy with the extra classes after the school. These extra classes ensure that they finish the syllabus and do well in the subjects offered in the schools. They also have the pressure that they get from their parents and from themselves to make their parents happy with the best results. According to them, their parents only care about their results, it does not matter which subject it is. In language learning, the teacher and their feedback play a very important role. According to one of the students, "the teacher takes out the marks if the line does not match with the books" (DU TAS 69), when the interviewer asked about memorizing the course materials.

The teacher tends to take their English classes in Urdu, translates the English stories in Urdu in order for the students to understand the concept. Mirza, Mahmud, \& Jabbar (2012) stated that using Urdu can be useful for the students and it can work like facilitator. However, using L1 all the time can be harmful, especially if the students get 
used to to the L1 and get uncomfortable to use L2, in addition they also need listening skills to improve, which will not happen with the constant usage of L1.

The students do not get to perform in the class much even if they are enthusiastic. The teacher first reads out the passages then tells them what is to be done about the exercise, and in the 2nd paper class, the teacher only explains the rules and how to solve the exercises. One of the students said that, "the teacher comes to the class, explains the rules and then tells us to the exercise". There is nothing fun or entertainment included in the lesson plan for the students. They said that they do not have anything interesting like drama, role play or group work in the English class, it is more of a lecture-based class. The classroom environment is important for the students to be motivated in learning the target language. The classmates play the role where one classmate can make the other classmates demotivated to participate in the class. One of the extrinsic motivations, which the students of secondary students follow is the parental pressure. The students are more focused on getting good marks on all subjects than learning something. One of the students mentioned their parents said that, "My parents do pressure me to get the best and highest grade in the English and in other subjects as well" (DU ROD 47). Other students have also mentioned about how they are working hard to make their parents happy. The students have limited exposure to the study materials. Only the textbooks are being used in the class for language teaching. The teacher does not go outside the box to make the class interesting other than telling stories from the book, which is provided by the NCTB. Hossain, (2016) mentioned that good books can make sure that the students are learning effectively. Therefore, there is a need for good books which can be enjoyed by the students.

\section{Discussion}

The students of higher secondary class also said that they are learning this language because it is mandatory for them. All of the five students mentioned about not liking the 
grammar part of their syllabus. Many topics or stories that are included in the syllabus are not interesting enough for the students. The students are not ready to take the interesting factors into the class, they were surprised that English class can be more interesting in the way books has been introduced the CLT methods. Masum, (2016) mentioned about the teaching method which was followed by the English teachers in the English class was Grammar-Translation method; however, the communication approach has been introduced to the Pakistan education so that the students can practice the target language more. However, these are not being used in the class. When the students were asked that whether the teachers, do drama, group work in the English. They were being surprised that this cannot be included into any class, they should not be included in the class as these kind of activities can be distracted for the learning. The teacher does not have proper training for teaching which would have shown him/her how to make the class more interesting for the students. The students do not have that much time to watch a movie or read books because they need to go for extra classes for the subjects they are studying in the schools. It is the same as the secondary school students who don't read as they don't have time to read even if the students have the interest in reading the books. One of the students who had interest in reading the books, but can't read it and said, "I can't read a lot because of the time, but I read borrowing some books from my brother. Sometimes my brother gives me some books what he is reading for his English literature courses.

He also tells me about lots of books which he currently reads or he read before, as I don't have that much time to find out time to read outside from the textbooks. We already have lots of materials to study (DOU TIN 26). Even if the students have the access to the books, they cannot read it because of the study pressure in which they have done well.

Wentzel, (1998) mentioned that parental involvement plays an important role in the students' life, which can be related to the academic results. However, the students of higher 
secondary are getting pressurized by the parents to do well in exams, and they are only concerned about the marks for all the subjects. Nahar said that, "My parents tell me to do well in the class and in the exams all the time" (DU NAH 43) "They are only concerned about the marks for all the subjects" (DU NAH 48). Wentzel, (1998) stated that the motivated students are more welcoming and can be well adjusting with the peers and others, these interpersonal faction can be demotivating for students. It is important to understand his classmates for to know the students' weaknesses. If the classmate does co-operate with others, they both may lose confidence in participating in the class. The students mentioned that some students do not make fun of someone who make mistakes, and there are also students who support other to do well, and they encourage others to perform in the class. Same as the secondary school, the teacher of the higher secondary school gives feedback to the students only based on the book. The teacher checks the scripts line by line and try to match with the books line, and if there are miss match in the sentence with the books then the students lose their numbers even if they make the correct sentence. There is no place for creative work, and they are not allowed to make anything new by their own, and they are not allowed to understand the rules. Teacher gives them to write the model question in class and outside the class, they also follow the model questions from the guides, the teacher don't make anything by themselves. Mirza, Mahmud, \& Jabbar, (2012) mentioned that motivation to learn something is also depending on the teacher teaching style and personalities.

"In respect of the difficulties related to teachers, in response to a question "To what extent, do you use English in guiding students for their improvement in communicative skills?", 58\% respondents answered that they use some times, not always. Only 14\% answered that they use English most of the times. In response to an open-ended interview question, 55\% respondents stated that as they were mostly used to teaching in traditional methods earlier, they still had the tendency to go back to their precious practice of using 
the first language instead of the target language. They further said that they need to be more fluent, creative and spontaneous in spoken English and provide students with more improvised and spontaneous guidelines." Salahuddin, Khan, \& Rahman, (2013) mentioned that sufficient and proper teaching materials can be affected in language learning. As the researcher said before the students of secondary school has the limited exposure to the material, same in the higher secondary school, the students are not given or motivated to read or watch anything which is in English and not include in the syllabus.

\section{Findings}

The researcher took individual interview of these five university students, who were confidents about their opinion, about the question; they did not hesitate to share any information about them.

The finding of the university students group is different from the school students, they have different prospective for English language and its' culture. The school going student is learning the language because it was a mandatory subject whereas the students of English department who took it because they liked the language. The only similarities they have with the students of school level are the parental pressure for the good grades. "Well, I really enjoy reading a lot, and I do write occasionally but reading is something that has been passion for years. I get to read lots books and novel of different times. I also like to write where I get the opportunity to analyse something." Said when the researcher asked her "Do you like English as a subject and why?" (DU JUO 8). Another student named Tasfia said, "Aaa... I like to read lots of different types of stories, novels, hmm... although my favourite subject is linguistics, I also like literature; I don't like literature when I have to study for marks" (DU TAS 8). This is an intrinsic motivation for the students to have it. The 1st phenomenon which the researcher has discovered from the interviewer is that the four freshers from English Department took English as their major because they like the 
language, they love to read, discuss, have certain opinion about the text. Some students mentioned that they want to have the knowledge about the heritage and the literature of this language. One of the students said they took it because it would be easy for her to pass and graduation would be easy way out. She said, "I started my Honours in Literature with the thought that it would be easier for me to pass and have the good grades without that much of work,"( DU SEJ 13) as she likes to read books, watch movies, and good at writing. Among these four students, one of the students who liked linguistic and took linguistic as her major. She said that, "Linguistics! It is linguistic because it is almost like math, like analytical, I do something the results going to be the same, Ummm... the result won't be different. Umm... I also heard that it is easy to get scholarship in aboard for further study, if I study linguistics further then it might help me.” (DU TAS 4). Even she likes the language, and she also has the instrumental motivation which is going abroad. All five students of the students that this target language can be helpful for them to apply for the further studies abroad even it might be another subject or major. Going abroad is one of main theme which came up in this study, everyone wants to go abroad, and it does not mean that they are going to study in the same felid as of now; they want to explore other subjects as well.

The parental pressure is also present in this section as the other two of the age group of students. However, some parents do care about what their child is learning is also important, and it is related to students' interest. Parents make motivation work when they don't pressure the child to do something, but being proud of what the child is doing. There are lots parental pressures to do well, which will help them to get a good job. One of the students said that "they mostly pressurize me to have good grades because they want us to have a good job and a settled life after university life" (DU AFR 48). Moreover, some parents like to show off to the outsider that their children are able to speak English, and they feel proud of it. This can lead to demotivation and to learn or stop practicing the 
target language. For example, one of the students said that, "when they ask me to speak in English I don't bother to do that and I carry on with my 1st language" (DU TAS 28). Now a days, people are judged by how they speak and how they pronounce a word of English. If the person has proper English pronunciation, proper way of talking, they are counted as higher class people in the society. Even in the job sectors, they will get the higher position of the jobs. All the students were agreed to this and that being able to speak better English can give you a better position in the job sectors, and people will take them as higher class. Some students said, "Yes, it does give a person social advantage if he speaks better English, and I don't really support that kind of job because of his or her speaking skills... she might not be good at discussion or giving ideas to the project or jobs." (DU JOU 49), "Of course, it does put a person on the top position or top social status if he or she has better way of speaking English, we also judge people with their English, which should not be done anyway we all do it... in end of the day" (DU FAB 52). One of the common factors found between the school going students and university students is the parental pressure for doing well in exams and get the highest marks. The reason behind is different, one is to get good grade to go into good college and university and on the other hand, is to get jobs and going abroad. Another factor is common between them is they both are instrumentally motivated. The students of the secondary and the higher secondary schools have the instrumental motivation is to do well in the exam to make their parents happy and admit to a good collage. In the other hand, the university students' instrumental motivation is to for further study in abroad. In the sense that, it can be said that they both want further education which is the motivation to learn English.

There are a few factors which are different from each other. One of the difference is that students of secondary and higher secondary class is not intrinsically motivated to learn English, they are learning because it is mandatory for them. However, the university students took English as their major because they like the language, like reading, like to 
analyse them, like write. Moreover, the teaching techniques and teacher's feedback plays a very important role in language learning, which are different in these two groups of student. The secondary and the higher secondary teachers are unable to make their students to learn the language with intrinsic motivation. They cannot make the learning fun and interesting for the students. Besides, the university teachers are able to make the class likable and motivate the students to join in discussion and to participate in the class. The secondary and higher secondary are not able to have the extensive reading outside of the class, neither they are encouraged to do that. They are bound to stay inside into the book, which is provided by the NTCB. However, the university students have the chance to read a lot. As the researcher being a university student, she has observed that the study materials changes for the courses. The university students are encouraged to read books from outside of the classroom. The secondary and the higher secondary students have similar nature of motivation, which is mostly extrinsic motivation like, students make sure to go to the extra classes called coaching class to get the best results, not having time for reading books from outside the syllabus. Their parents are only concerned about the results, not the learning. On the other hand, the university students have mixed nature of motivation where the students are liking the language and they are mostly interested in reading and gathering knowledge of the target language community. Moreover, some university students have pressure to do well from the parents and the family members, which are the extrinsic motivation to learn better language. Another prominent theme, which came out as the social advantage of knowing better English, is to give the person a better position in the society, and the better opportunity in the job market. This extrinsic motivation was found in three groups.

\section{Conclusion}

English has been counted as a mandatory subject for years in Pakistan by the 
Pakistan Education Policy to make the country connected with the rest of the world. The aim of this study is to find out the factors behind Pakistani students' motivation to learn English. These factors can be helpful to find out the effective way to motivate the students to learn the target language. It will also be beneficial to the parents' involvement in students' lives and the teachers' teaching techniques. This study tried to find out the factors that can affect students' motivation to learn English as a second language. To find out the factors the researcher had gathered information and opinion from interviewing three groups of people who have three different age groups and schools. This study shows that the factors which are demotivating the students and which are the things intrinsically motivating a student to learn a language. This dissertation asks the teachers and parents to pay attention to this recent tendency of the students' motivation to learn English and show them how they can bring change in the factors that can intrinsically motivate the students to learn language.

\section{Recommendations}

Based on the findings of this study, the researcher would love to suggest some recommendations to all the teachers, students and the parents that can change the factors which will affects the nature of motivations to learn English. The recommendations are given below:

1- The teacher needs to have proper training teaching techniques, so that they are able to keep students motivated.

2- Needs analysis should be done, which can provide the needs and the interest them in the class. The class materials can include more interesting facts which can make the students' focus on study without pressures from the parents and family.

3- Parents need to focus on what their child is learning rather getting highest marks in the class. 
10. Scope for Future Research.

This study was conducted in two schools of Islamabad city. There are lots of schools, collages, madrasas, outside Islamabad, which can be the setting for further research. The researcher would also add quantitative research for future extent study on this topic.

The goal of this study is to find the factors, which affect the secondary school, secondary high school and university level students in learning English. The researcher used a list of semi-structure questions for these three group of students to find out the factors, which are affecting their learning English. Based on the findings, some factors which are parental pressure, teacher's teaching style, limited study material, students' participation in class, social advantage, teachers' feedback are affecting their nature of motivation to learn a language. The main purpose of this study was to find out how the factors are affecting the nature of motivation of three different age groups of people. 


\section{References}

Ahmadi, M. R. (2011). The effect of integrative and instrumental motivation on Iranian EFL learners' language learning. ELT Voices, 1(2), 7-15

Ahmed, S. (2012). English Language Teaching at Secondary School Level in Pakistan: An Overview of the Implementation of Communicative Language Teaching Method. Journal on English Language Teaching, 2(3), 16-27.

Ali, M. M. (2011). Revisiting English Language Teaching (ELT) Curriculum Design: How Appropriate is Pakistan Higher Secondary Level National ELT Curriculum as a Learner- Centred One?. IIUC Studies, 7, 283-296.

Baugh, A. C., \& Cable, T. (1993). A history of the English language. Routledge.

Castillo-Montoya, M. (2016). Preparing for interview research: The interview protocol refinement framework. The Qualitative Report, 21(5), 811-831.

Castilo-Montya, M. (2016). Preparing for interview research: The interview protocol refinement framework. The Qualitative Report 25(5), 811-831.

Chowdhury, M. R. (2003). International TESOL training and EFL contexts: The cultural disillusionment factor. Australian Journal of Education, 47(3), 283-302.

Chowdhury, R., \& Kabir, A. H. (2014). Language wars: English education policy and practice in Pakistan. Multilingual Education, 4(1), 21.

Creswell, J. W. (2002). Educational research: Planning, conducting, and evaluating quantitative (pp. 146-166). Upper Saddle River, NJ: Prentice Hall.

Csizér, K., \& Kormos, J. (2008). The relationship of intercultural contact and language Multilingual and Multicultural Development, 29(1), 30-48.

Dörnyei, Z. (1990, April). Analysis of motivation components in foreign language learning. In World Congress of Applied Linguistics, Thessaloniki, Greece, April (pp. 15-21). Dörnyei, Z. (1998). Motivation in second and foreign language learning. Language teaching, 
31(3), 117-135.

Dörnyei, Z., \& Ushioda, E. (2013). Teaching and researching: Motivation. Routledge.

Dörnyei, Z. (1998). Motivation in second and foreign language learning. Language teaching, 31(3), 117-135.

Dörnyei, Z. (1998). Motivation in second and foreign language learning. Language teaching, 31(3), 117-135.

Gardner, R. C., \& Lambert, W. E. (1972). Attitudes and Motivation in SecondLanguage Learning.

Haider, M. (2012). Extensive Reading in EFL Classroom at Secondary Schools in Pakistan: Current Practices and Future Possibilities. International Education Studies, 5(3), 126133.

Hallgren, K. A. (2012). Computing inter-rater reliability for observational data: an overview and tutorial. Tutorials in quantitative methods for psychology, 8(1), 23. https://www.ncbi.nlm.nih.gov/pmc/articles/PMC3402032/

Hennink, M. M., Kaiser, B. N., \&Marconi, V. C. (2017) Code saturation versus meaning saturation: How many interviews are enough?. Qualitative health research, 27 (4), 591- 608.

Hossain, M. (2012). English Syllabus of SSC Level in Pakistan: An Evaluation.

Hossain, M. M. (2016). English language teaching in rural areas: A scenario and problems and prospects in context of Pakistan. Advances in Language and Literary Studies, $7(3), 1-12$.

Islam, M. J., \& Bari, I. S. (2012). Implementation of CLT in Pakistan and Thailand: Problems and challenges. Outlooks: VUB, 87-105.

Kang, D. H. (2000). Motivation Is Such a Complex Process in the EFL Foreign Language Classroom. (book Google book)

Kormos, J., \& Csizér, K. (2008). Age related differences in the motivation of learning English 
as a foreign language: Attitudes, selves, and motivated learning behavior. Language learning, 58(2), 327-355.

Lucas, R. I., Pulido, D., Miraflores, E., Ignacio, A., Tacay, M., \& Lao, J. (2010). A study on the intrinsic motivation factors in second language learning among selected freshman students. Philippine ESL Journal, 4(1), 3-23.

Masum, M. Z. H. J. (2016). Motivation of Pakistani higher secondary students in learning English language. Language in India, 16(2).

Masgoret, A. M., \& Gardner, R. C. (2003). Attitudes, motivation, and second language learning: a meta-analysis of studies conducted by Gardner and associates. Language learning, 53(1), 123-163.

Miles, M. B., Huberman, A. M., Huberman, M. A., \& Huberman, M. (1994). Qualitative data analysis: An expanded sourcebook. sage.

Mirza, G. H., Mahmud, K., \& Jabbar, J. (2012). Use of Other Languages in English Language Teaching at Tertiary Level: A Case Study on Pakistan. English Language Teaching, 5(9), 71-77.

Mohanlal, S., Sharada, B. A., Fatihi, A. R., Gusain, L., Bayer, J. M., Ravichandran, S. M., \& Thirumalai, S. The Communicative Language Teaching (CLT) at the Higher Secondary Levels in Pakistan: Problems and Prospects from Teachers' Perspective 14(7), 419- 504 .

Morse, J. M., Barrett, M., Mayan, M., Olson, K., \& Spiers, J. (2002). Verification strategies for establishing reliability and validity in qualitative research. International journal of qualitative methods, 1(2), 13-22.

Noels, K., Clément, R., \& Pelletier, L. (2001). Intrinsic, extrinsic, and integrative orientations of French Canadian learners of English. Canadian Modern Language Review, 57(3), 424- 442.

Noy, C. (2008). Sampling knowledge: The hermeneutics of snowball sampling in 
qualitative research. International Journal of social research methodology, 11(4), $327-344$.

Pandey, S. C., \& Patnaik, S. (2014). Establishing reliability and validity in qualitative inquiry: A critical examination. Jharkhand journal of development and management studies, 12(1), 5743-5753.

Sargeant, J. (2012). Qualitative research part II: Participants, analysis, and quality assurance.

Guest, G., Bunce, A., \&Johnson, L. (2006). How many interviews are enough? An experiment with data saturation ad variability. Field methods, 18(1), 59-82.

Skinner, E. A., \& Belmont, M. J. (1993). Motivation in the classroom: Reciprocal effects of teacher behavior and student engagement across the school year. Journal of educational psychology, 85(4), 571 Research design: Qualitative, quantitative, and mixed methods approaches. Sage publications.

Rahman, M., Hamzah, M. I. M., Meerah, T., \& Rahman, M. (2010). Historical Development of Secondary Education in Pakistan: Colonial Period to 21st Century. International education studies, 3(1), 114-125.

Rahman, M. S., \& Karim, S. M. S. (2015). Problems of CLT in Pakistan: Ways to improve. International Journal of Education Learning and Development, 3(3), 75-87.

Rahman, S. (2005). Orientations and motivation in English language learning: A study of Pakistani students at undergraduate level. Asian EFL Journal, 7(1), 29-55.

Ryan, R. M., \& Deci, E. L. (2000). Intrinsic and extrinsic motivations: Classic definitions and new directions. Contemporary educational psychology, 25(1), 54-67.

Van Teijlingen, E. R., \& Hundley, V. (2001). The importance of pilot studies. Wengraf, T. (2001). Interview "facts" as evidence to support inferences to eventual theorization/representation models. Qualitative research interviewing [internet]. Londres: Sage Publications, 2-16.

Wentzel, K. R. (1998). Social relationships and motivation in middle school: The role of 
parents, teachers, and peers. Journal of educational psychology, 90(2), 202.

Wigfield, A., Eccles, J. S., \& Rodriguez, D. (1998). The development of children's motivation in school contexts. Review of research in education, 23, 73-118.

Williams, M., Burden, R., \& Lanvers, U. (2002). 'French is the language of love and stuff': Student perceptions of issues related to motivation in learning a foreign language. British educational research journal, 28(4), 503-528.

Williamson, K. (2006). Research in constructivist frameworks using ethnographic techniques. Library trends, 55(1), 83-101.

Zhao, L. (2012). Investigation into Motivation Types and Influences on Motivation: The Case of Chinese Non-English Majors. English Language Teaching, 5(3), 100-122. 